\title{
El cuerpo sufriente como lugar de memoria en Fe en disfraz, de Mayra Santos-Febres
}

The Suffering Body as 'Lieu de mémoire' in Mayra Santos-Febres' Fe en disfraz

O corpo sofredor como lugar de memória em Fe en disfraz (Fe de fantasia), de Mayra Santos-Febres

\section{Patricia Valladares-Ruiz}

\section{UNIVERSITY OF CINCINNATI, ESTADOS UNIDOS}

Profesora de literaturas del Caribe hispano y francófono en la Universidad de Cincinnati, Estados Unidos. PhD, Université de Montréal, Canadá. Ha publicado Sexualidades disidentes en la narrativa cubana contemporánea (Támesis, 2012), El tránsito vacilante (coeditado con Leonora Simonovis, Rodopi, 2013) y la colección de ensayos AfroHispanic Subjectivities (2011). Ha publicado artículos en revistas académicas como Modern Language Notes, Monographic Review, Inti, Revista Hispánica Moderna, Revista Iberoamericana, Romance Quarterly, eHumanista, Letras Femeninas, La Torre, Neophilologus e Hispania. Correo electrónico: Patricia.Valladares-Ruiz@uc.edu doi:10.11144/Javeriana.cl20-40.csIm 


\section{Resumen}

Este artículo propone una lectura detenida de la novela Fe en disfraz (2009), de Mayra Santos-Febres, con el propósito de examinar el reciclaje de un pasado esclavista que denuncia tanto el proceso de erotización de las relaciones de dominación y sumisión como la reproducción de estas dinámicas en las sociedades poscoloniales. En este contexto, el artículo explora las posibles subversiones de las dinámicas tradicionales de poder en las relaciones interraciales.

\section{Palabras clave: Mayra Santos Febres; esclavas; lugar de memoria; abuso sexual; dominación y sumisión; cuerpo sufriente; literatura puertorriqueña}

\section{Abstract}

This article examines the entanglement of fiction and historical memory. More particularly, it analyses how Santos-Febres' literary representation of slavery confronts traditional malecentered narratives, while reproducing the myth of the eroticized mulatta. Furthermore, this article focuses on how the (re/de)construction of sexual abuse of slave women challenges traditional sexual, gender, racial, and social dynamics in postcolonial societies.

Keywords: Mayra Santos-Febres; female slavery; lieu de mémoire; sexual abuse; domination and submission; suffering body; Puerto Rican literature

\section{Resumo}

Este artigo propõe uma leitura detida no romance Fe en disfraz (2009), de Mayra SantosFebres, com o propósito de examinar a reciclagem de um passado escravista denunciando tanto o processo de erotização das relações de dominação e submissão quanto a reprodução dessas dinâmicas nas sociedades pós-coloniais. Neste contexto, o artigo explora as possíveis subversões das dinâmicas tradicionais de poder nas relações inter-raciais.

\section{Palavras-chave: Mayra}

Santos Febres; escravas; lugar de memória; abuso sexual; dominação e submissão; corpo sofredor; literatura portoriquense

RECIBIDO: 17 DE AGOSTO DE 2015. ACEPTADO: 1 DE OCTUBRE DE 2015. DISPONIBLE EN LÍNEA: 1 DE JULIO DE 2016

\section{Cómo citar este artículo:}

Valladares-Ruiz, Patricia. "El cuerpo sufriente como lugar de memoria en

Fe en disfraz, de Mayra Santos-Febres". Cuadernos de Literatura 20.40

(2016): 595-616. http://dx.doi.org/10.11144/Javeriana.cl20-40.cslm 
LA OBRA NARRATIVA de Mayra Santos-Febres se ha caracterizado por el tratamiento transgresor de personajes que desafían la marginalidad a la que están condenados. Bien sea por su condición social, racial, sexual o de género, en anteriores novelas - como Sirena Selena vestida de pena (2000), Cualquier miércoles soy tuya (2002) y Nuestra Señora de la Noche (2006) - los personajes protagónicos de Santos-Febres denuncian y subvierten las estructuras hegemómicas de dominación.

En respuesta al tratamiento literario de la imagen turística de un Caribe plagado de lugares paradisíacos y supurante sensualidad, Santos-Febres - en lugar de rechazarlos - opta por explorar estos tópicos para impregnarlos de aquello que considera un saber alternativo de la especificidad de las culturas caribeñas. A juicio de la autora, este rasgo común en sus novelas responde a los lineamientos estéticos y temáticos de su proyecto literario:

Opino que muchos de los escritores caribeños hacen una de dos cosas: tratan de irse por encima de ese estereotipo y niegan una realidad caribeña — escriben entonces novelas muy nostálgicas, que niegan la cuestión del deseo y del cuerpo y se alejan de tratar temas de raza, religión, cotidianidad caribeña. Yo eso lo entiendo, porque se quieren salir del condena'o estereotipo que nos tiene encarcela'os. Mi respuesta es otra: tratar de incluir las cosas que se piensan como exóticas y develarlas como un tipo de conocimiento diferente: hay una risa, un gozo, una manera de pensar el deseo y experimentar el cuerpo de manera diferente que es tan valiosa como la de cualquiera. Ahí es donde me sitúo, porque no quiero ser otra cosa que caribeña. ("Libertad enmascarada"s. p.)

Como resultado de esta visión de las identidades caribeñas - y de los $c a$ ribetemas que las alimentan - las novelas de Santos-Febres exploran relaciones interpersonales que evocan (por adscripción y, sobre todo, por subversión) las dinámicas coloniales que definen las aún vigentes jerarquías raciales, genéricas y sexuales. Sin embargo, esta caribeñidad - que reconocemos tanto en su ficción como en sus ensayos - está muy lejos de ser introspectiva. Por el contrario, el Caribe de Santos-Febres navega y atraca en otros parajes para alimentarse de ellos y, sobre todo, para instalar un diálogo global y cosmopolita. Precisamente, al preguntársele acerca de la representación de una espacialidad caribeña en su escritura, Mayra Santos-Febres afirma:

[T]here is Wilson Harris and Édouard Glissant, Simone Schwarz-Bart, Evelyne Trouillot and others who have written about or are working on Caribbean stories and idiosyncrasies, but I still feel that there is much to do in the field. There is also the task of entering into global discussions and inserting 
these stories and "knowledges" into a global context. That is the task I am most interested in. ("Más allá" 147)

En esta agenda ideoestética se inscribe Fe en disfraz (2009). En la lectura de esta novela examino el reciclaje de un pasado doloroso que denuncia tanto el proceso de erotización de las relaciones de dominación (hombres blancos) y sumisión (mujeres afrodescendientes) como la reproducción de estas dinámicas en las sociedades poscoloniales. En este contexto, planteo la exploración detenida de las posibles subversiones de las dinámicas tradicionales de poder en las relaciones interraciales.

Esta novela corta de tintes eróticos gira en torno a la explotación sexual de esclavas en Brasil, Costa Rica, Venezuela y Colombia. En la narración no lineal se entrecruzan eventos del pasado (ocurridos entre los siglos XVII y XVIII en colonias españolas y portuguesas) y el presente (en Chicago, Madrid y San Juan de Puerto Rico). En esta ocasión, Santos-Febres expande los horizontes antillanos dentro de los cuales se inscriben sus anteriores novelas para incorporar en Fe en disfraz referencias a otros contextos culturales de América Latina, Europa y Estados Unidos.

El argumento de esta novela gira en torno a dos personajes: Martín Tirado, el narrador-protagonista, un historiador que llega a Chicago para trabajar bajo las órdenes de Fe Verdejo, investigadora y organizadora de una exposición sobre esclavas manumisas. Martín se ocupa de los archivos del seminario de investigación que documenta esta exposición. El recorrido al pasado es justificado, entonces, por el descubrimiento de documentos históricos que revelan las atrocidades que sufrieron las esclavas a mano de sus amos. Mientras Martín lee cada una de las historias de aquellas esclavas, advierte la excitación que le producen estos testimonios, casi todos caracterizados por el maltrato físico y el abuso sexual que padecieron aquellas niñas y mujeres.

Una lectura epidérmica de esta novela sugeriría que la atracción que siente Martín por Fe - mujer metódica, reservada y mulata de imponente figura - es la consecuencia natural de una fantasía recién descubierta y que tiene mucho que ver con dinámicas de dominación y sumisión como fuentes de erotismo. Asimismo, la caracterización racial de la protagonista introduce el paralelismo, por medio de un juego de espejos, que se nutre de las historias de las manumisas y de la vida de Fe Verdejo. Como se verá en este análisis, esta posibilidad sugeriría también el desplazamiento de ambos personajes protagónicos por zonas de poder que van desde la subordinación hasta el dominio absoluto en el plano laboral y, más particularmente, en el sexual. 
En Fe en disfraz, el tratamiento de la esclavitud y la representación de mujeres esclavizadas se articula a partir de un esfuerzo posmoderno por cuestionar, reordenar y parodiar la historia oficial. Esta empresa se estructura en torno a series de acciones que podrían agruparse de la siguiente forma: los eventos del pasado (las agresiones que sufren las esclavas manumisas), los documentos históricos (las denuncias de estas agresiones), la recepción del documento (el descubrimiento y la reacción que produce la lectura de estas denuncias), la exhibición (el archivo y exposición de los documentos y trajes de las esclavas) y la puesta en escena de los episodios de dominación sexual (interpretadas por Fe y Martín).

En esta caracterización del pasado esclavista, Fe Verdejo es el hilo conductor y cohesionador de los distintos mecanismos de exploración de las memorias: la letrada/intelectual, la ancestral/emocional y la espectacular. A diferencia de otras novelas históricas posmodernas, ${ }^{1}$ en su representación del pasado esclavista, Fe en disfraz transciende el examen de episodios dolorosos del pasado para trasladarlos al presente, explorando su carácter documental, exhibiéndolos y reinterpretándolos desde el presente. En la novela de Santos-Febres el acto liberador no ocurre en el espacio colonial - como consecuencia de la abolición-, sino en el presente, como resultado de la reinterpretación de las relaciones de poder definidas por el sistema de jerarquías raciales.

La obsesión por hacer públicas las denuncias de las esclavas manumisas y organizar una exposición con todo el material recolectado es, en primera instancia, el propósito del trabajo de investigación documental de Fe Verdejo. Por medio de las historias de estas manumisas, las referencias a la esclavitud operan como lo que Pierre Nora denominara lieux de mémoire (lugares de memoria), es decir, espacios marcados por rituales en una sociedad con tendencia a economizarlos (12). Desde el presente narrativo y afincada en un locus de enunciación otro, Fe (re)crea un rito en torno a un trauma cultural que se nutre tanto de sus investigaciones como de sus memorias (afectiva, cultural e, incluso, erótica). A partir de este momento, la narración transita entre la historia (representada en los legajos encontrados), la recuperación performativa de un trauma colectivo y la desarticulación de dinámicas de poder que trascendieron a lo largo de los siglos. ${ }^{2}$ El elemento discursivo que une los dos principales ejes argumentales - las

$1 \quad$ En este conjunto de novelas históricas posmodernas destacan Memorias de Lucila (Beatriz Berrocal, 1996), Santa Lujuria (Marta Rojas, 1998), La renuncia del héroe Baltasar (Edgardo Rodríguez Juliá, 1974), La loma del ángel (Reinaldo Arenas, 1985), L'esclave vieil homme et le molosse (Patrick Chamoiseau, 1997) y, entre otras, Moi, Tituba sorcière (Maryse Condé, 1986).

2 Las vidas de las esclavas manumisas transcurren entre los siglos XVII y XVIII. 
historias de las esclavas (pasado) y la relación entre Fe y Martín (presente) - es un misterioso traje del siglo XVIII.

Entre las tantas anotaciones que mantiene Martín sobre las esclavas manumisas, destacan sus apuntes sobre Fe Verdejo. La protagonista se encuentra, por lo tanto, tan documentada como los otros sujetos de la exposición que organiza. Al principio de la narración, Martín relata la relación que ambos sostienen. Posteriormente, sus notas se van concentrando en la historia del origen de Fe y, más precisamente, la historia del traje de Fe. De esta forma, el recorrido de un disfraz que alguna vez fuera el vestido ostentoso del debut en sociedad de varias esclavas manumisas opera como uno de los principales hilos argumentales de $\mathrm{Fe}$ en disfraz. El uso simbólico de este vestido llega incluso a señalar a Xica da Silva como la primera portadora de un traje que signaría, a la manera de un conjuro, las vidas de las sucesivas portadoras y como una alegoría al pasado colonial. ${ }^{3}$

Este traje, la pieza más aclamada de la exposición, llega a manos de Fe gracias a una monja mulata y muy anciana. La mujer en cuestión decía ser hija y nieta de monjas: "Aun así, nació ella, y nació su madre. Nació toda su casta. Todas monjas y putas" (24). De acuerdo con el relato sobre el vestido, varias esclavas y sus descendientes eran internadas en conventos, posiblemente para esconder la vergüenza que suponía ser víctima de abusos sexuales. Esta referencia apunta a la concepción tradicional del noviciado como el oficio privilegiado para quienes, como estas jóvenes, tenían vedada cualquier posibilidad de ascenso social, como consecuencia de su situación familiar, su raza o su precaria situación económica. Las religiosas que atesoraban el vestido reconocían en él poderes mágicos asociados a las historias dolorosas de sus portadoras. Justamente por ello, al recibir el traje, la protagonista es objeto de una retahíla de advertencias:

- Te recomiendo que nunca te lo pongas - me dijo la monja, sin saber que su advertencia era tardía-. Ese traje está habitado. Los arneses y la tela han bebido demasiado sudor y demasiadas penas. Dicen que es el que usó la misma Xica da Silva cuando la presentó Fernandes de Oliveira por primera vez en sociedad [... Él] quería que Xica respirara lujo, que aquel traje espantara todo recuerdo de esclavitud del cuerpo de su amante. Ella se prestó. Hizo lo que pudo para aprender a llevarlo con el garbo de una señora. Confió en que el traje le bastaría. Pero la mona, aunque la vistan de seda...

3 Una de las explotaciones simbólicas más relevantes del traje apunta a la metáfora del tráfico y el valor de cambio del sujeto esclavizado. Para una amplia reflexión sobre este tema pueden consultarse los estudios de Eric Williams y David Eltis. 
- La monja intentó reírse, pero se ahogó en su propio aire. Pasó un largo rato antes de que pudiera continuar su confesión.

- [Ella] era su mujer verdadera, pero el Estado de aquella época no permitía casamientos entre blancos y negras. (77)

La referencia a Xica da Silva ${ }^{4}$ es particularmente significativa, si se toma en cuenta la tradicional construcción discursiva que se ha hecho de ella en cuanto estandarte de la armonía racial. Al respecto, Júnia Ferreira Furtado sostiene que se ha usado el mito de Xica para sostener que los vínculos afectivos entre blancos libres y negras contribuyeron al declive del sistema esclavista en Brasil (xxiii). No obstante, Ferreira también advierte que: "a pesar del provecho económico que [...] pudieron suponer para algunas de estas mujeres, estas relaciones impusieron una doble explotación (tanto racial como sexual), debido a que nunca eran ascendidas al rango de esposas" (xxiii; la traducción es mía). Este impedimento, como hemos visto, también es recogido en la historia que cuenta la monja y en las denuncias de las esclavas y manumisas que sostuvieron relaciones con sus antiguos amos.

$\mathrm{Fe}$-conocedora de estos antecedentes y desatendiendo las recomendaciones de la monja - se apropia del traje y hace de él un lugar de memoria, para decirlo en palabras de Pierre Nora. La protagonista no puede evitar caer en la tentación de reproducir en carne propia el dolor y el desafuero sexual que durante siglos había habitado aquel vestido. Esto es posible apreciarlo en las narraciones de los encuentros sexuales entre Fe y Martín. Estos ocurren entre el 31 de octubre y el 1 de noviembre, fechas que coinciden con la fiesta de Samhain, ${ }^{5}$ además de otras celebraciones como Halloween, el Día de Todos los Santos y la víspera del Día de los Fieles Difuntos.

Como parte del ritual amatorio, Fe se viste parsimoniosamente con el antiguo traje en presencia de su amante. Un elemento importante de esta ceremonia es un arnés de cuero y varillas que Fe porta en cada ocasión. Este ajustado artilugio inflige laceraciones sangrantes en los muslos y las entrepiernas de Fe; heridas que, después del acto sexual, Martín lame celosamente. Si bien estos gestos se convierten en un elemento de una alta carga erótica para ambos, una de sus mayores contribuciones es, como se ha dicho, la desarticulación de dinámicas de

4 Entre las representaciones de Francisca da Silva de Oliveira (c. 1732-1796) son de necesaria mención el libro Memórias do districto diamantino de Joaquim Felício dos Santos (1868), la obra teatral O tesouro de Chica Silva de Antônio Calado (1962), el largometraje Xica de Carlos Diegues (1976) y la telenovela Xica da Silva (1996-1997).

5 Samhain es una antigua festividad pagana de origen celta que celebra el final de la temporada de cosechas. 
poder y, por otra parte, su capacidad de vehicular dramáticamente la rabia y el trauma histórico alimentado por siglos de abusos físicos y sexuales. El siguiente es uno de los pasajes que mejor ilustra lo anteriormente señalado:

Con una mano, Fe apretó las correas del arnés contra su carne. Frunció el ceño. Su piel se arrugó contra las bandas, mudando de color, enrojeciéndose. Un golpe de sangre hirvió entre sus piernas. Fe apretó aún más el arnés y echó un poco la cabeza hacia atrás, mordiéndose los labios. Las varillas se hundieron en su carne. Asomaron los primeros abultamientos, las primeras gotas de sangre [...] Entonces, mi jefa procedió a vestirse con el traje amarillo de seda [...] Acto seguido se puso a gatas. Empezó a lamerme los pies, luego, las pantorrillas, las rodillas, los muslos, las entrepiernas. Yo, preso del rito, no hacía más que jadear, sabiendo que, con cada caricia, la piel de Fe recibía un mordisco del arnés, que levantaba en una nueva herida [...] No pude contenerme. Me vacié en su boca, como una ofrenda.

Luego, hablamos un rato. Más bien, habló ella. Yo me limité a lamerle las heridas. $(57-58)$

Mientras que "Fe Verdejo pagaba en sangre el placer de dar placer" (58), Martín, por su parte, descubría el placer de dominar sexualmente a su amante: "Su sumisión me levantó un dragón por dentro. No pude evitar preguntarme si ese dragón era yo, si el de mentira era el otro Martín Tirado" (59). En primera instancia, el dolor se presenta como una consecuencia directa de la búsqueda del gozo sexual, pero también como la representación y apropiación del sufrimiento de los ancestros de Fe. Por otra parte, una interpretación alternativa del simbolismo asociado al disfraz sugeriría que - en lugar de propiciar la puesta en escena de las relaciones entre amos y esclavas - es precisamente el antiguo traje de Xica el elemento liberador de una Fe que es presa de esa otra investidura/impostura que ha ido construyéndose en la esfera pública a través de los años. Si en novelas como Mes quatre femmes (Gisèle Pineau, 2007), Le livre d'Emma (Marie-Célie Agnant, 2001) y Doña Inés contra el olvido (Ana Teresa Torres, 1992) la revisión de los eventos pasados responden a un acto irracional y meramente volitivo; en contrapartida, en Fe en disfraz, la formación intelectual y desempeño profesional de la protagonista imponen un manejo aparentemente racional de estos hechos históricos. ${ }^{6}$ Sin embargo, a través de su rito anual, la Fe observadora e investigadora del inicio de la novela abre paso a una $\mathrm{Fe}$ ancestral, impulsiva y arrebatada por sus pulsiones sexuales.

6 A propósito de la intervención de Fe Verdejo en el sistema de conocimiento del pasado, son de necesaria consulta los estudios de Chrissy Arce y Rangelova Radost. 
La exploración erótica de dinámicas de dominación y sumisión (D/S) es la puerta de entrada a este recorrido por las vidas atormentadas de las esclavas que habitan tanto los archivos de Martín como el mítico traje de Xica da Silva. ${ }^{7}$ A propósito del fetichismo asociado a las dinámicas sadomasoquistas (S/M), las reflexiones de Anne McClintock resultan esclarecedoras en el análisis de los rituales amatorios que sostienen Fe y Martín:

Consensual $S / M$ insists on exhibiting the 'primitive' (slave, baby, woman) as a character in the historical time of modernity. S/M stages the 'primitive irrational' as a dramatic script, a communal performance in the heart of Western reason. The paraphernalia of $S / M$ (boots, whips, chains, uniforms) are the paraphernalia of state power, public punishment converted to private pleasure. (91)

En línea con esta definición, en $F$ e en disfraz las prácticas de D/S operan como un territorio propicio para que Fe detenga el tiempo, reinterprete un pasado traumático y lo subvierta. En apariencia, se trataría de una fantasía de sumisión y, posteriormente, una negociación del poder en la relación sexual. No obstante, cada una de las descripciones de estos encuentros indicaría que, en cualquiera de los casos, Fe decide y controla cómo van a distribuirse los roles sexuales en la pareja.

La protagonista recrea, entonces, el espacio que ocupa en la relación con Martín, para luego tambalearlo y cuestionarlo. Con todo, quizá mucho más significativa es la reapropiación alegórica desde el artificio erótico de los abusos físicos que sufrieron las esclavas. Hay que tomar en cuenta que solo Fe es la encargada de dosificar e, incluso, agudizar su propio dolor. ${ }^{8}$ En este juego sexual, Martín no interpreta el papel de un amo dominante, sino que funciona como un elemento más de un ritual orquestado por Fe.

Si hablar del pasado esclavista desde la perspectiva de una escritora afrodescendiente puede ser objeto de cuestionamiento, erotizar el trauma colonial y potenciar el estereotipo de las negras y mulatas sensuales podría resultar doblemente conflictivo. A propósito de la publicación de Fe en disfraz, Santos-Febres mencionaba que uno de sus temores era justamente ser acusada de remover

7 Para un análisis exhaustivo de las intersecciones de poder, relaciones de género y violencia sexual en el contexto caribeño, consúltese el estudio de Paula Morgan y Valerie Youssef.

8 Otra interpretación de estos encuentros sugeriría la puesta en escena de una relación homoerótica - siempre adscrita a las dinámicas D/S - entre Fe y la(s) esclava(s) de sus archivos. En tal caso, Martín conservaría su condición de elemento accesorio en estas relaciones sexuales. 
innecesariamente eventos del pasado, especialmente si estos se relacionan con la experiencia esclavista: ${ }^{9}$

Tenía miedo de que me dijeran: ¿Por qué vas a escribir de algo que ya está superado? [...] Tenía miedo a que pensaran: "Esta es una negra que escribe" en vez de "una escritora negra" $[\ldots]$ La puerta del erotismo me sirvió para entrar por fin al tema del esclavismo, pero eso no quiere decir que haya superado el miedo. No quería acercarme a la esclavitud desde lugares esperados: no quería la denuncia. ("Mayra Santos-Febres jamás")

En Fe en disfraz, el acercamiento al tema de la esclavitud, desde la época contemporánea, plantea no solo la inversión de las relaciones opresivas entre esclavas y amos, sino también un cuestionamiento de cómo estas dinámicas se han reciclado y transgredido. Se partiría, entonces, de la idea de tensiones raciales estrechamente vinculadas a la diferencia sexual; una dicotomía que, de acuerdo con Evelynn Hammonds, se encargaría de apuntalar la supremacía del hombre blanco (95). Visto así, la reproducción de estereotipos relacionados con la hipersexualidad de las afrodescendientes permitiría justificar la esclavitud, las violaciones y otras formas de abusos por parte de hombres blancos (Hammonds 96).

Con estos antecedentes, la relación entre Fe y Martín desestabilizaría, en primer término, las jerarquías raciales heredadas del periodo colonial, ${ }^{10}$ tanto por tratarse de una mujer negra y jefa, en oposición a un hombre blanco y subalterno, como por ser partícipes de una dinámica sexual anormativa. Estaríamos ante un fenómeno de redistribución de un poder determinado por la raza, el sexo y la clase - factores que condicionan la asignación tradicional de roles en las relaciones heterosexuales-. Conviene tener en cuenta la advertencia de Judith Butler sobre la construcción de la sexualidad en el contexto de las relaciones de poder.

Para la autora de Fe en disfraz este tema ha sido muy poco abordado en la literatura del Caribe hispano, a diferencia de otras literaturas de la región; sobre todo si se toma en cuenta - como lo apunta la propia Santos-Febres- la carencia de escritoras negras en el Caribe hispanohablante ("Mayra Santos-Febres jamás").

10 A este respecto, es de incuestionable relevancia la postura de Santos-Febres ante la representación literaria de la esclavitud femenina: "Si solo pensamos la esclavitud sexual hacia las negras desde el punto de vista de la violación, no estamos viendo el panorama completo. Todavía hoy hay una situación tensa, dolorosa, pero llena de complicidades y de amor, porque el amor también se da" ("Mayra Santos-Febres jamás"). Desde esta óptica, destaca la importancia de la referencia a Xica da Silva (y su larga relación con João Fernandes de Oliveira) en el conjunto de historias de las esclavas manumisas. Asimismo, la relación entre Fe y Martín contribuiría, por una parte, a desarticular la distribución colonial del poder (sexo, raza y clase) y, por la otra, a plantear una dinámica conciliadora afincada en el carácter lúdico y transgresor de sus juegos de roles. 
Desde esta perspectiva, una sexualidad normativa anterior, ajena o más allá del poder, es una imposibilidad cultural. Se pospondría, entonces, la inscripción de subjetividades subversivas en tales términos (30).

Sin embargo, en esta lectura también hay que tomar en cuenta el carácter performativo de las prácticas $\mathrm{S} / \mathrm{M}$ y D/S. Como se puede advertir en la novela, el personaje de Fe interpreta el rol sumiso en sus primeras relaciones heterosexuales. Martín se presenta, justamente, como el interlocutor ideal para reproducir esos primeros escarceos amorosos y, no menos importante, Martín se convierte en el eco perfecto para saciar nuevas fantasías que surgen con el descubrimiento de los documentos de las esclavas. Como resultado de estas inquietudes, Fe orquesta y dirige los rituales de $\mathrm{D} / \mathrm{S}$ entre amo y esclava. $\mathrm{Si}$, como hemos visto, Martín interpreta el papel de amo, no es menos cierto que también él es vasallo de las pulsiones sexuales de su jefa. Pese a todo, Martín asume con entusiasmo el rol de agresor en la recreación de aquellas escenas del pasado. En esta lectura es preciso considerar tanto el potencial desestabilizador de lo que se define en el ámbito S/M como switch (conmutador) como el cuestionamiento de los roles tradicionalmente asociados a las categorías de género y sexuales (Hopkins 130). Caracterizado/a por su versatilidad, el/la switch tiene la capacidad de desplazarse a lo largo de diferentes zonas - desde la extremadamente activa/dominante a la extremadamente pasiva/sumisa - y, en la práctica, demostraría que estos roles sexuales no están exclusivamente vinculados al género, raza o carácter de sus intérpretes. Podemos apreciar este proceso en uno de los encuentros entre Martín y Fe, cuando esta última se convierte en la dueña de Martín. En este pasaje, Fe le pide a Martín que se arrodille y la descalce. Él sigue atentamente sus instrucciones, le lame las piernas y las heridas producidas por el arnés del traje. En medio del clímax sexual, Fe le pide a Martín que la libere. A partir de ese momento surge una escisión en la relación erótica entre ambos. El ritual amatorio persigue, ya no rememorar los tormentos de las esclavas, sino liberar a Fe de ese pasado:

La navaja en mis manos [...] La desnudaré completa. Contaré las telas de ese traje [...] Fe gritará, le taparé la boca [...] Se desvanecerán cicatrices y humillaciones. Entonces, Fe, liberada, entenderá y se abrirá para mí. Ella misma lo ha querido. Me lo ha pedido todo este tiempo: "Rompe el traje, desgárralo, sácame de aquî". Me hundiré dentro de ella hasta que gritemos juntos. Hasta que olvidemos juntos quiénes hemos sido. Abandonar es, a veces, la única manera de comenzar. (114-115)

Si en el ámbito sexual Fe transita a su antojo el amplio espectro comprendido entre la dominación y la sumisión; por su parte, Martín la invita a alejarse 
del territorio del recuerdo para finalmente librarse del dolor ancestral que se materializa en el ritual en el que ambos participan cada año.

Ya desde el inicio de la novela encontramos referencias a las visiones de los protagonistas acerca del pasado. Aunque ambos se interesen por el examen de documentos y objetos históricos, Fe se interesaría más por la exploración de la memoria cultural. En cambio, Martín opta por una visión monumental de la historia, y aunque en apariencia pueda resultar contradictorio, también elige el olvido - al menos el de $\mathrm{Fe}$ - como único camino hacia el futuro. Con sus encuentros sexuales, los protagonistas no solo persiguen la puesta en escena y reinterpretación del pasado, sino también el cuestionamiento de las tensiones sociales, raciales y de género. La descripción que Martín hace de su trabajo parecería responder a este propósito:

Recompongo (e ilustro) fragmentos del pasado. Los ofrezco al presente en tiempo hiperreal, un tiempo que pretende burlar la muerte de lo orgánico, la quietud del papel, la lentitud de los hechos [...] Vivo (como un monje) suspendido en el tiempo [...] Vivo callado, embebido en los mudos designios de la Historia. (17)

El argumento de $\mathrm{Fe}$ en disfraz se define a partir de este constante contrapunteo entre el hecho histórico, la memoria ancestral, el olvido y la representación/reinterpretación del pasado. Santos-Febres acomete esta tarea desde una perspectiva intrahistórica a la que Luz Marina Rivas se ha referido como "la reescritura de la historia de personajes anónimos y de sus vidas torcidas por la historia colectiva" (61). Como se verá en la segunda parte de este artículo, los legajos que recogen las denuncias de las manumisas nos hablan de personajes aparentemente desconocidos y de víctimas tradicionalmente silenciadas en la historiografía sobre el periodo colonial. El personaje de Fe Verdejo se encarga, precisamente, de rescatar estas historias del anonimato para exhibirlas tanto en el ámbito público (en la exposición que organiza) ${ }^{11}$ como en el privado (en sus encuentros con Martín en su particular celebración del Samhain).

11 A propósito del potencial simbólico de las piezas de la exhibición pública que organiza Fe Verdejo, conviene considerar, de acuerdo con Vivian N. Halloran, la capacidad de estos objetos de recrear la ilusión de que los espectadores son también testigos del pasado: "Through exhibitions showcasing artwork, historical artifacts, and other objects associated with slavery and the slave trade, museums and historical novels construct a space in which visitors/readers can overcome their sense of belatedness and self-righteousness by acting like witness to the past" (20). 


\section{Cicatriz, memoria y deseo: las denuncias de las esclavas manumisas}

Como he mencionado, entre cada uno de estos episodios entre Martín y Fe se entrelazan las denuncias de las esclavas manumisas. Cuatro de estas narraciones se presentan como anotaciones tomadas de archivos oficiales, libros de consultas de un colegio religioso en Mérida (Venezuela), documentos municipales o registros históricos de ciudades como Minas Gerais (Brasil), Valle de Matina (Costa Rica) o Cartagena de Indias (Nueva Granada). En cada legajo se identifica a la víctima de los abusos o, en el caso contrario, a la beneficiaria de alguna herencia. En estos documentos se clasifica a las mujeres de acuerdo con su origen racial, se expone su condición de esclavas y reciben los nombres de sus amos o cónyuges. Una de las preocupaciones de $\mathrm{Fe}$, en cuanto investigadora y curadora, es la imposibilidad de encontrar material gráfico que pueda ofrecer una imagen de estas mujeres. Se correría, entonces, el riesgo de que - al no tener un rostro conocido- permanezcan invisibles y no alcancen a formar parte de la historia.

La primera de estas semblanzas es la de Diamantina, una esclava de Minas Gerais, quien en 1785 denuncia a su ama por maltratos físicos sobre ella y uno de sus hijos. Tres cicatrices en su mejilla sugerirían un origen fula o fulani, un pueblo del África occidental. El documento indica que anteriormente Diamantina había solicitado protección real al gobernador por los abusos de su ama: "En esa ocasión, declaró la esclava: 'que la señora no para de injuriarme, de pegarme con un palo sobre el vientre y empujarme para ocasionarme caídas"' (28). El interrogatorio de doña Antonia, ama de Diamantina, revelaría un asunto de celos por la relación que sostenía su marido, Tomás de Angueira, con la esclava. Las siguientes declaraciones de doña Antonia reflejarían la caracterización prejuiciosa de las negras a partir de una mítica voracidad sexual y desvergüenza:

Los había visto "en el acto", él pinchándole la carne, mordiéndole los pechos y ella gritando como las "callejeras de la calle", como acostumbras las que son de su clase $[\ldots]$ las negras, personas sujetas a servidumbre, viles, de baja suerte, atrevidas y desvergonzadas [...] las criadas corruptas como callejeras pues en realidad lo son que así son estas mujeres todas y como tal se comportan. $(28)^{12}$

12 El desprecio y revanchismo de doña Antonia determina la suerte de Diamantina, incluso después de la muerte de su ama. En su testamento, doña Antonia pide que la esclava sea vendida y que con el dinero se cubran los gastos del funeral y sepelio. Sin embargo, don Tomás alega que la esclava en aquel momento ya había compensado con su trabajo su precio de venta. Como consecuencia de esto, don Tomás le otorga la libertad tanto a Diamantina como a sus cinco hijos (29). 
El motivo de la declaración de la esclava manumisa en 1785 es, en primer lugar, para notificar el fallecimiento de Tomás de Angueira y, acto seguido, para solicitar el cumplimiento del testamento en el que su antiguo amo declara a los hijos de Diamantina como los herederos universales de sus bienes (29). La mulatez de los hijos de Diamantina sugeriría que ellos son el producto de la relación con su patrón. Desde luego, la historia de esta esclava manumisa convoca algunos de los mayores temores de la sociedad colonial: las relaciones interraciales, el ataque a la pureza racial, el usufructo de las fortunas blancas por partes de afrodescendientes y el consecuente ascenso social de estos últimos. Novelas como Santa lujuria, de Marta Rojas, y Doña Inés contra el olvido, de Ana Teresa Torres, inscriben relaciones similares entre acaudalados amos blancos y esclavas que también son objeto de ataques por parte de la sociedad criolla,justamente por el temor a ver tambaleada la jerarquía racial imperante.

Por otra parte, la historia de Diamantina presenta varios puntos en común con la vida de Xica da Silva. El nombre del personaje de Fe en disfraz coincide con Diamantina, el actual nombre de la ciudad donde naciera Xica, anteriormente conocida como Arraial do Tejuco y privilegiado centro de producción de diamantes durante el periodo colonial (Ferreira 12). Así, tanto el personaje histórico como el de la novela de Santos-Febres provienen de la región de Minas Gerais, fueron pobres y esclavas de nacimiento, sostuvieron relaciones y procrearon varios hijos con sus respectivos amos acaudalados; gracias a sus servicios sexuales fueron manumitidas, heredaron grandes fortunas y lograron ascender en la escala social. Es preciso recordar que, en la capitanía de Minas Gerais, durante el siglo XVIII - periodo en el que transcurren las vidas de Xica y Diamantina - abundaron las manumisiones vinculadas a los concubinatos entre amos blancos y esclavas. ${ }^{13}$ En contraste con otras de las historias reseñadas en los archivos que revisa Martín, Diamantina participa activa y gozosamente en sus encuentros con Tomás de Angueira; mientras que otras manumisas relatan los abusos sexuales de sus amos blancos. A semejanza del personaje histórico de Xica da Silva y las protagonistas de las novelas de Ana Teresa Torres (Doña Inés contra el olvido) y Marta Rojas (Santa lujuria), Diamantina habría explotado su supuesta hipersexualidad para seducir a su amo y adueñarse de su fortuna.

$13 \mathrm{Al}$ respecto, Ferreira Furtado precisa que estas relaciones fueron la vía más común para que las esclavas de la región pudieran obtener su libertad (15-16). Como consecuencia de estas uniones, el número de habitantes mestizos de la región aumentó considerablemente (Ferreira Furtado 16). 
Posteriormente en la narración, Martín descubre un documento histórico que señalaría a Xica como la dueña original del antiguo traje de Fe Verdejo. El placer que experimenta el protagonista con la lectura de las declaraciones de las esclavas aumenta considerablemente cuando se topa con la historia de la verdadera Xica. Los datos, aunque imprecisos y en ocasiones alterados, apuntan evidentemente a la información biográfica que se conoce de la esclava brasileña: "Nacida en 1731 o 1735, no se conoce la fecha exacta. Hija de María da Costa, negra esclava, y Caetano de Sá, portugués, [...] esclava del médico de Arraial de Tejuco, don Manuel de Pires, quien la tomó como amante siendo ella apenas una niña de once años" (41). En la detallada descripción de los abusos denunciados destacan la pederastia, prácticas lésbicas forzadas (para el disfrute del amo), además de una variedad de desafueros sexuales que le valieron la reprimenda del vicario del pueblo.

En este capítulo encontramos uno de los momentos de mayor tensión dramática y erótica de la novela que permite aclarar el origen del vestido y su relación con Fe: "Acabé de leer el documento. Mi piel se encandiló entera. Traté de aplacarla tocándome como siempre. Fue, entonces, que descubrí el documento adjunto [...] Era una fotografía en detalle del disfraz de Fe; es decir, del traje de Xica, el reencontrado. Miré el traje, miré la piel, miré a la niña corrompida" (42). La excitación que le produce la imagen de la niña evocaría las prácticas pederastas de los amos de varias de las denuncias que conserva en sus archivos electrónicos. Este paralelismo alimenta la dinámica relacional basada en la dominación e imposición sexual del hombre blanco sobre la mujer negra. En su estudio seminal sobre la esclavitud, Orlando Patterson compara este vínculo con una forma de parasitismo, donde el poder se manifiesta en la influencia psicológica que reside exclusivamente en una persona, el amo $(307,335)$. Sin embargo, en el caso de Martín, la erotización que le supone el ejercicio del control queda relegada a un segundo plano, debido a que - como ya he dicho- en sus encuentros con Fe, Martín se dedica a complacer los designios de su amante desde su pretendida impostura dominante.

Si las historias de las esclavas de Minas Gerais dan indicios del origen del traje de Fe Verdejo, la cuarta denuncia —y la más antigua - es la que más contribuye con el desenlace de la novela. Se trata de Pascuala, una esclava mulata que en 1645 fue enviada de Mérida (Venezuela) a la cárcel del Castillo de la Barra en Maracaibo (Venezuela). Se la acusaba de haber hechizado con sus efluvios corporales al hijo adolescente de un hacendado. ${ }^{14}$ Para evitar que otros hombres fueran víctima de

14 "Después de una serie de torturas en varias zonas de su cuerpo, incluyendo los genitales, las autoridades del Santo Oficio determinaron los contubernios de Pascuala con Lucifer" (62). 
sus embrujos, el Santo Oficio aconsejó precaución y distancia en el trato diario con Pascuala (63). Como puede apreciarse, estos relatos alimentan el mito de la mulata hipersexual, capaz de embrujar al hombre blanco con sus artes amatorias.

Para contribuir a la circularidad de la novela, el último de los documentos recogidos proviene de la misma región que la historia anterior, aunque sus acciones ocurren siglos más tarde y, esta vez, giran en torno a la figura de la protagonista, María Fernanda Verdejo. Así, pues, en Maracaibo alrededor de 1985, la abuela de Fe la interna en un colegio de monjas. Sigue así la tradición de las mujeres de su familia, quienes tuvieron que abandonar el convento tras salir embarazadas de sus respectivas hijas. Todo apuntaría a que $\mathrm{Fe}$, al igual que su traje, es el producto de una casta de mujeres abusadas y castigadas por la sociedad. ${ }^{15}$

La infancia y adolescencia de Fe influyen claramente en sus relaciones adultas. A manera de ejemplo, la descripción que Fe hace de su primera experiencia sexual señala el inicio de su búsqueda del placer a través del sometimiento: "Tengo que admitir que me gustó aquella derrota. Aquella sumisión dolorosa, aquel dejarme hacer. No opuse demasiada resistencia" (9o). Este capítulo dedicado a la adolescencia de Fe ilustra su necesidad de aprehender el pasado, su relación con las historias de las esclavas y una sexualidad que convoca el dolor para convertirlo en gozo.

Los archivos históricos que comparten Fe y Martín revelan ciertas coincidencias, como lo son la pederastia, los abusos sexuales por parte de hombres blancos, el enfrentamiento y rivalidad entre mujeres negras y blancas. ${ }^{16}$ Por muy aciagas que sean algunas de las anécdotas relatadas, cada una de ellas ofrece una vía de escape, aunque en algunos casos apenas se trate del otorgamiento de la protección real. En este conjunto destacan, como se ha dicho, las historias de Diamantina y, en mayor medida, la de Xica y la de la propia Fe. Las tres mujeres coinciden en su esfuerzo por sobreponerse a la sumisión y asumir un rol activo en su sexualidad. Esta actitud trasciende el plano sexual para impactar

Tras varias horas de sufrimiento, la esclava confesó que había atraído a los jóvenes con sus hechizos: "Admitió que propinaba sus polvos a mancebos decaídos para poder cosechar sus jugos en la boca o entre sus piernas y, con ellos, destilar, pociones de fertilidad para su variada clientela. Que pedía clemencia divina. Mostró signos de genuina contrición" (63).

El capítulo dedicado a la infancia de Fe recoge siglos de rechazo social, en este caso, acentuado por ser la única niña negra y pobre del internado religioso.

16 La sexualidad femenina de la mujer negra fue construida en oposición a los atributos de pureza y castidad asociados a las mujeres blancas, quienes a su vez debían actuar como guardianas de los valores morales y religiosos de la raza blanca (Carby 20-39; Blassingame 154-173; Clinton 94). Para un estudio de la representación literaria de la rivalidad entre mujeres blancas y esclavas negras puede consultarse el estudio de Jennifer Fleischner, Mastering Slavery. 
favorablemente su ascenso social, como es el caso de Lucila, la protagonista de Santa lujuria.

Sin embargo, el dolor físico producido por el acto violento es el vínculo más sólido entre cada una de las historias de las manumisas y — de vital trascendencia en la narración - la conexión con los orígenes de Fe Verdejo. En este escenario, la única posibilidad que tiene la historiadora de acercarse a este tragedia es hacerla propia; no solamente a través de la memoria cultural y emocional, pero también en un cuerpo sufriente que arrastra un dolor del pasado hasta el presente, en su afán de adueñarse del trauma histórico hasta lograr superarlo.

En su análisis de la representación de la esclavitud en la literatura puertorriqueña contemporánea, Zaira Rivera-Casellas reflexiona acerca de la carga simbólica del traje que porta Fe en los ritos amatorios de cada 31 de octubre: "En el caso de Fe, la transformación mediante la envestidura reincide en abrir las cicatrices que han quedado impresas en su piel cada vez que sangra al llevar el vestido. Las heridas abiertas despiertan el dolor del pasado, pero como un gesto necesario para imponerse a la renovación de la memoria racial" (113). Esta perspectiva es particularmente relevante si se toma en cuenta que el descubrimiento de las confesiones de las manumisas y la posterior reinterpretación espectacular de Fe y Martín se convierten en gestos emancipadores que encuentran un eco en narrativas posmodernas sobre la esclavitud. Como lo indica perspicazmente Angelyn Mitchell, el centro de atención de estos textos no es precisamente la esclavitud, sino la construcción de aquello que entendemos por libertad (3): ${ }^{17}$

I define the liberatory narrative as a contemporary novel that engages the historical period of chattel slavery in order to provide new models of liberation by problematizing the concept of freedom. I prefer the term liberatory narrative as the contemporary narratives are more than "new": they are more complex in form and content that the eighteenth-and nineteenth-century slave narratives. (4)

Fe en disfraz se afiliaría a estas narrativas posmodernas en su esfuerzo por desarticular las narrativas del amo, reapropiarse del legado de la esclavitud y subvertirlo hasta convertirlo en un emblema de la mujer negra empoderada. Desde esta óptica, la participación de Martín en esta empresa es crucial. En los últimos encuentros sexuales, el amante incita a Fe a comenzar un lento proceso

17 En su estudio de estas narrativas liberadoras, Mitchell analiza detenidamente un corpus de novelas de finales del siglo XX escritas por autoras afrodescendientes: Kindred (1979), de Octavia E. Butler; Dessa Rose (1986), de Sherley Anne Williams; Beloved (1987), de Toni Morrison; Family (1991), de J. California Cooper, y The Price of a Child (1995), de Lorene Cary. 
de cicatrización que la encamine a una emancipación corporal y emocional definitiva: "Haré que mi dueña olvide quién ha sido. Historiadora famosa, aprendiz de monja, niña vejada. Le haré sudar su vergüenza hasta que brame sin palabras desde el otro lado de su miedo, desde el otro lado de su soledad" (115). Martín se suma a esa invitación a deslastrarse del pasado, un gesto que le permitiría renunciar a una dinámica erótica en la que se ha desempeñado como amo y cautivo.

Sin embargo, la travesía hacia la emancipación es un pasaje largo y doloroso. A través del performance Fe logra enfrentarse a un pasado, dominarlo, hacerlo suyo y -si la invitación de Martín llega a buen término- ser capaz de deshacerse de él para enfrentar el presente. De esta forma, la esclavitud -o más precisamente, la reconstrucción espectacular del pasado esclavista que interpreta Fe Verdejo- se transmuta en el tributo inquietante a una libertad que se sabe frágil y en constante negociación. En esta línea, críticos como Ron Eyerman y Arlene Keizer han advertido la capacidad del pasado esclavista de definir la historia colectiva de los afrodescendientes americanos y caribeños, sirviendo así como un punto de referencia constante, aunque su significado pudiera haber variado a través del tiempo. Pero no es hasta mediados del siglo XX cuando la esclavitud logra trascender la demarcación de una memoria grupal para confrontar límites, ritos y lugares de la memoria pública (Eyerman 18; Keizer 5). A esta tarea contribuye ampliamente Mayra Santos-Febres con Fe en disfraz. Recordemos que varios de los textos publicados a finales del siglo XIX y en la primera mitad del XX pretendían responder a las llamadas narrativas de los amos para exponer los horrores de la empresa esclavista, "limpiar" la imagen de los sujetos afrodescendientes y definirlos a partir de atributos como pureza, heroicidad, dignidad, lealtad y afán de superación. ${ }^{18}$ Santos-Febres no renuncia a los tropos comunes de las anteriores narrativas abolicionistas, sino que se apropia de ellos para diseccionarlos, confrontarlos y problematizarlos. En esta empresa, destaca el esfuerzo por desvictimizar la imagen de negras esclavizadas que, como lo sugieren los legajos de Fe y Martín, son capaces de sobreponerse a los maltratos y abusos sexuales a los que fueron sometidas.

El reclamo más significativo de $\mathrm{Fe}$ en disfraz no se encuentra, pues, en la denuncia de las atrocidades cometidas a las esclavas, sino en la explotación simbólica de la exhibición museística y en la exploración del potencial erótico de las

18 Ejemplos de esta tendencia son textos como: $S a b$ (Gertrudis Gómez de Avellaneda, 1841), La cuarterona (Alejandro Tapia y Rivera, 1867), El negro Francisco (Antonio Zambrana, 1875), En el cafetal (Domingo Malpica, 1890), Pobre negro (Rómulo Gallegos, 1937) y Cumboto (Ramón Díaz Sánchez, 1950). 
relaciones de poder entre el hombre blanco y la mujer negra. El tratamiento del tema de los abusos sexuales, en apariencia atrevido y políticamente incorrecto, es el vehículo para una revisión de los elementos constitutivos de la identidad de la protagonista - como su condición de género, sexualidad, raza, clase y oficio-. En esta travesía, a Fe ya no le bastan sus herramientas intelectuales para examinar el padecimiento de las manumisas de sus archivos. En cambio, por medio de la puesta en escena de la violencia sexual, parece desdoblarse hasta el punto de reconocerse en una experiencia traumática que deja de ser ajeno. ${ }^{19}$ Así, solo una noche al año, Fe se retrotrae al pasado para avivar el dolor de su estirpe, imponerse al olvido y para que ese abandono - como lo advierte Martín- la devuelva a una vida renovada.

Al distanciarse de los usos nacionalistas y épicos del tema esclavista, Santos-Febres da voz, palabra y cuerpo a una mujer negra que alcanza a sobrevivir las cadenas, los abusos sexuales, la experiencia migratoria y el paso del tiempo. En Fe en disfraz salta a la vista un esfuerzo deliberado por empoderar al personaje afrodescendiente, sin que por ello el mito de la convivencia armoniosa entre los grupos raciales y los géneros deje de ser un proyecto postergado. Desde esta perspectiva, me gustaría sugerir que una de las mayores contribuciones de $\mathrm{Fe}$ en disfraz apunta a la articulación intelectual de nuevas dinámicas de racialización en el contexto latinoamericano y caribeño, al tiempo que confronta la retórica tradicional que refuerza la supremacía del hombre blanco.

\section{Obras citadas}

Agnant, Marie-Célie. Le livre d'Emma: Roman. Montreal:

Éditions du Remue-ménage, 2001. Impreso.

Arce, Chrissy. "La fe disfrazada y la complicidad del deseo". Lección errante:

Mayra Santos-Febres y el Caribe contemporáneo. Eds. Nadia Celís y

Juan Pablo Rivera. San Juan: Isla Negra, 2011. 226-246. Impreso.

Arenas, Reinaldo. La loma del ángel. Miami: Universal, 1995. Impreso.

19 En "Violent Liaisons: Historical Crossings and the Negotiation of Sex, Sexuality, and Race" Sam Vásquez ofrece un agudo análisis de la representación literaria del legado de la experiencia esclavista y su impacto en la relación entre violencia y sexualidad femenina en el contexto caribeño; "I argue that contemporary violence and the ways violence is worked out on the body are rooted in the barbarities of colonial slavery. Focusing on racialized and sexualized Caribbean bodies that receive scant critical attention, I contend that for these individuals, desire and difference are inextricably intertwined and analytically inseparable from the violence that contextualizes this intertwining, and that, out of necessity, these women have used such paradigms for survival" (45). 
Avancini, Walter y Jacques Lagôa, dir. Xica da Silva. Intér. Tais Araújo, Drica

Moraes, Víctor Wagner. Río de Janeiro: Rede Manchete, 1996-1997. Filme.

Berrocal, Beatriz. Memorias de Lucila, una esclava rebelde. San

Juan: Taller Nacional de Creación, 1996. Impreso.

Blassingame, John W. The Slave Community: Plantation Life in the Antebellum

South. Nueva York: Oxford University Press, 1972. Impreso.

Butler,Judith. Gender Trouble: Feminism and the Subversion of

Identity. Nueva York: Routledge, 1990. Impreso.

Butler, Octavia E. Kindred. Boston: Beacon Press, 1979. Impreso.

Callado, Antônio. O tesouro de Chica da Silva: peça em 2 atos. Rio de Janeiro: Sociedade Brasileira de Autores Teatrais, 1962. Impreso.

Carby, Hazel V. Reconstructing Womanhood: The Emergence of the Afro-American Woman Novelist. Oxford: Oxford University Press, 1987. Impreso.

Cary, Lorene. The Price of a Child. New York: A. A. Knopf, 1995. Impreso.

Chamoiseau, Patrick. L'esclave vieil homme et le molosse. París: Gallimard, 1997. Impreso.

Clinton, Catherine. The Plantation Mistress: Woman's World in the Old South. New York: Pantheon Books, 1982. Impreso.

Condé, Maryse. Moi, Tituba, sorcière, noire de Salem. París: Mercure de France, 1986. Impreso.

Cooper, J. California. Family. New York: Doubleday, 1991. Impreso.

Díaz Sánchez, Ramón. Cumboto: cuento de siete leguas.

Buenos Aires: Nova, 1950. Impreso.

Diegues, Carlos, dir. Xica. 1976. Intérp. Zeze Mota y Walmor

Chagas. Nueva York: New Yorker Video, 1993. Filme.

Eltis, David. "The Relative Importance of Slaves and Commodities in the Atlantic Trade of Seventeenth-Century Africa". Fournal of African History 35.2 (1994): 237-249. Impreso.

Eyerman, Ron. Cultural Trauma: Slavery and the Formation of African American Identity. Cambridge, UK: Cambridge University Press, 2001. Impreso.

Ferreira Furtado, Júnia. Chica da Silva: A Brazilian Slave of Eighteenth Century. Nueva York: Cambridge University Press, 2009. Impreso.

Fleischner, Jennifer. Mastering Slavery: Memory, Family, and Identity in Women's

Slave Narratives. Nueva York: New York University Press, 1996. Impreso.

Gallegos, Rómulo. Pobre negro [1937]. Caracas: Panapo, 2009. Impreso.

Gómez de Avellaneda, Gertrudis. Sab. 1841. Ed. José

Servera. Madrid: Cátedra, 2007. Impreso.

Halloran, Vivian N. Exhibiting Slavery: The Caribbean Postmodern Novel as

Museum. Charlottesville, VA: University of Virginia Press, 2009. Impreso. 
Hammonds, Evelynn M. "Toward a Genealogy of Black Female Sexuality: The Problematic of Silence". Feminist Theory and the Body: A Reader. Eds. Janet Price y Margrit Shildrick. Nueva York: Routledge, 1999. 93-104. Impreso.

Hopkins, Patrick D. "Rethinking Sadomasochism: Feminism, Interpretation, and Simulation". Hypatia 9.1 (1994): 116-141. Impreso.

Kanor, Fabienne. Humus. Paris: Gallimard, 2006. Impreso.

Keizer, Arlene R. Black Subjects: Identity Formation in the Contemporary

Narrative of Slavery. Ithaca, NY: Cornell University Press, 2004. Impreso.

Malpica La Barca, Domingo. En el cafetal. La Habana:

Los Niños Huérfanos, 1890. Impreso.

McClintock, Anne. "Maid to Order: Commercial Fetishism and

Gender Power". Social Text 37 (1993): 87-116. Impreso.

Mitchell, Angelyn. The Freedom to Remember: Narrative, Slavery, and Gender in Contemporary Black Women's Fiction. New

Brunswick, NJ: Rutgers University Press, 2002. Impreso.

Morgan, Paula y Valerie Youssef. Writing Rage: Unmasking Violence through Caribbean

Discourse. Kingston, Jamaica: University of West Indies Press, 2006. Impreso.

Morrison, Toni. Beloved. New York: Knopf, 1987. Impreso.

Nora, Pierre. "Between Memory and History: Les Lieux de Mémoire". Representations 26 (1989): 7-25. Impreso.

Patterson, Orlando. Slavery and Social Death: A Comparative Study.

Cambridge, MA: Harvard University Press, 1982. Impreso.

Pineau, Gisèle. Mes quatre femmes. Paris: P. Rey, 2007. Impreso.

Radost, Rangelova. "Writing Words, Wearing Wounds: Race and Gender in a Puerto Rican Neo-Slave Narrative". Tinkuy 18 (2012): 150-158. Impreso.

Rivas, Luz Marina. La novela intrahistórica. Mérida,

Venezuela: El Otro Mismo, 2004. Impreso.

Rivera-Casellas, Zaira. "La poética de la esclavitud (silenciada) en la literatura puertorriqueña: Carmen Colón Pellot, Beatriz Berrocal, Yolanda Arroyo Pizarro y Mayra Santos Febres". Cincinnati Romance Review 30.Special Issue on Afro-Hispanic Subjectivities (2011): 99-116. Impreso.

Rodríguez Juliá, Edgardo. La renuncia del héroe Baltasar. México, D. F.: Fondo de Cultura Económica, 2006. Impreso.

Rojas, Marta. Santa Lujuría o Papeles de blanco. La

Habana: Letras Cubanas, 1998. Impreso.

Santos, Joaquim Felício dos. Memórias do districto diamantino da comarca do Sêrro

Frio, Província de Minas Gerais. Río de Janeiro: Typ. Americana, 1868. Impreso. 
Santos-Febres, Mayra. Cualquier miércoles soy tuya.

Barcelona: Mondadori, 2002. Impreso.

Santos-Febres, Mayra. Fe en disfraz. Doral, Fl.: Alfaguara, 2009. Impreso.

Santos-Febres, Mayra. "Libertad enmascarada: entrevista de Dean Luis Reyes". La

Firibilla. Revista de Cultura Cubana 32 (Dec. 2001). Web. 12 de mayo de 2012.

Santos-Febres, Mayra. "'Más allá de la información': Region, Culture and the Imagination. An Interview". Perspectives on the 'Other America': Comparative Approaches to Caribbean and Latin American Culture. Eds. Michael Niblett y Kerstin Oloff. Ámsterdam: Rodopi, 2009. 147-154. Impreso.

Santos-Febres, Mayra. "Mayra Santos-Febres jamás se ha disfrazado de un personaje. Entrevista de Héctor Aponte Alequín". Primera

Hora 12 de diciembre de 2009. Web. 2 de octubre de 2010.

Santos-Febres, Mayra. Nuestra Señora de la Noche. Madrid: Espasa, 2006. Impreso.

Santos-Febres, Mayra. Sirena Selena vestida de pena.

Barcelona: Mondadori, 200o. Impreso.

Tapia y Rivera, Alejandro. La cuarterona: drama original en tres

actos. 1867. San Juan: Instituto de Cultura Puertorriqueña;

Editorial de la Universidad de Puerto Rico, 1993. Impreso.

Torres, Ana Teresa. Doña Inés contra el olvido. Caracas: Monte Ávila, 1999. Impreso.

Williams, Eric E. Capitalism \& Slavery. New York: Russell \& Russell, 1961. Impreso.

Williams, Sherley Anne. Dessa Rose. New York: William Morrow, 1986. Impreso.

Zambrana, Antonio. El negro Francisco: novela original de costumbres cubanas.

Santiago, Cuba: Imprenta de la Librería del Mercurio, 1875. Impreso.

Vásquez, Sam. "Violent Liaisons: Historical Crossings and the Negotiation of Sex, Sexuality, and Race". Small Axe 38 (2012): 43-59. Impreso. 